\title{
ХАРАКТЕРИСТИКА СОЦИАЛЬНО-ПСИХОЛОГИЧЕСКОГО ПРОСТРАНСТВА КАК УСЛОВИЯ РЕАЛИЗАЦИИ МЕЖКУЛЬТУРНОГО ВЗАИМОДЕЙСТВИЯ В ОРГАНИЗАЦИИ
}

\section{CHARACTERISTIC OF SOCIAL AND PSYCHOLOGICAL SPACE AS A CONDITION FOR IMPLEMENTING INTERCULTURAL INTERACTION IN THE ORGANIZATION}

O. Korol

Summary: The results of an empirical study of the socio-psychological space as a condition for the implementation of intercultural interaction in industrial organizations are presented. It is shown that the concept of socio-psychological space is variable in content, but its universals can be used to analyze the whole variety of complex structures of intercultural interaction of various social communities. Diagnostic techniques have been tested, which make it possible to objectify the essential components and basic elements of the socio-psychological space in their dynamic and hierarchical relationship.

Keywords: psychological space, socio-psychological space, structure of psychological space, real parameters of psychological space, ideal parameters of psychological space, behavior, intercultural interaction.

\author{
Король Ольга Феликсовна \\ К.nсх.н., дочент, ГБОУ ВО Республики Крым «Крымский \\ инженерно-педагогический университет им. Февзи \\ Якубова», г. Симферополь \\ korololga2008@gmail.com
}

Аннотация: Представлены результаты эмпирического исследования социально-психологического пространства как условия реализации межкультурного взаимодействия в организациях промышленной сферы. Показано, что понятие социально-психологического пространства вариативно по содержанию, но его универсалии могут быть использованы для анализа всего многообразия сложных конструкций межкультурного взаимодействия различных социальных общностей. Апробированы диагностические приемы, позволяющие объективировать сущностные компоненты и основные элементы социально-психологического пространства в их динамическом и иерархическом соотношении.

Ключевые слова: психологическое пространство, социально-психологическое пространство, структура психологического пространства, реальные параметры психологического пространства, идеальные параметры психологического пространства, поведение, межкультурное взаимодействие.

с особенностями взаимоотношении людей в активном взаимодействии [3 - 4]. Социальное пространство, как многомерный феномен рассматривал и П. Бурдье с позиции структурирования различных полей. Автор, определяя аспекты социума, связанные с распределением материальных ресурсов (реальность первого порядка) и существующие в сознании людей (реальность второго порядка), описывает социальное пространство через топологию структурной диспозиции полей: экономического, политического, культурного, интеллектуального и т.д. [цит. по 5 с. $18 ; 8$, с.35].

Здесь заметим, что и Гидденс и Бурдье, рассматривая структурирование социального пространство, не включают в поле своего исследовательского внимания активность социальных агентов [цит. по 19, с.147 - 149]. В то время как Г. Зиммель, написавший работу «Социология пространства» подчеркивает, что социальное пространство - это бездейственная форма, существующая лишь благодаря энергии деятельности субъектов [цит. по 20, с 47 - 49].

Именно на активности коллективного субъекта деятельности акцентирует свое внимание и П. Штомпка, 
подчеркивая, что взаимодействие субъектов происходи не только в социальном пространстве, но и в физическом (объективном) времени, а также в социальном времени, качественно субъективном [цит. по 1, с.23].

Проблеме социального пространства уделяет большое внимание П.А. Сорокин: «Социальная мобильность есть перемещение индивида внутри социального пространства... определить положение человека или какого-либо социального явления в социальном пространстве означает определить его (их) отношение к другим людям и другим социальным явлениям, взятым за такие «точки отсчета». Сам же выбор «точек отсчета» зависит от нас: ими могут быть отдельные люди, группы или совокупность групп» [17, с. 298].

Необходимо отметить, что основное свойство социального пространства, которое выделяет П.А. Сорокин, - многомерность. Однако наиболее явными, по мнению автора, являются вертикальные и горизонтальные параметры. «Разграничение вертикальных и горизонтальных параметров отражает явления, действительно существующие в социальной вселенной: иерархии, ранги, доминирование и субординация, авторитет и послушание, повышение и понижение по службе. Все эти явления и соответствующие им взаимозависимости представлены в виде стратификации и суперпозиций. Для описания таких связей необходимы и удобны вертикальные параметры. С другой стороны, взаимосвязи, свободные от таких элементов, можно описать в горизонтальных параметрах» [17, с. 301].

Таким образом, делая краткий вывод, отметим, что понятие социально-психологического пространства вариативно по содержанию, но мы можем вполне использовать его универсалии для анализа всего многообразия сложных конструкций межкультурного взаимодействия различных социальных общностей.

\section{Методы исследования}

Использовались теоретические методы исследования: теоретико-методологический и логический анализ, обобщение, классификация, конкретизация, построение аналогий, моделирование; эмпирические методы

\section{^итературный обзор}

Предметом современных психологических исследований является множество «психологических пространств существования человека, как общих, универсальных, так и частных, специализированных видов пространства, выделяемых в результате анализа взаимодействия субъекта с конкретными сферами жизнедеятельности человека. Журавлев А.Л. подчеркивает, что «в концептуальных моделях и программах эмпирических исследований многих современных авторов можно отметить явный рост внимания к ценностно-смысловым и духовно-нравственным компонентам личности и группы» $[6$, с. $51-81]$

Гораздо реже в научной литературе затрагиваются вопросы онтогенеза групповой и индивидуальной вариативности психологического пространства, роли возрастных закономерностей и профессиональных интересов в процессе развития и структурирования психологического пространства. Однако, существует достаточное количество классификаций социальных процессов. Так, например, классификация, предложенная Леопольдом фон Визе, в основу которой положены принципы конструкции и деструкции, систематизирующие все процессы, связанные с изменениями социальных структур.

Анализ данной системы классификации показывает, что различные процессы качественного перехода социальных процессов, например, от состояния закрытости структур к их открытости, сближению и объединению предполагает наличие не только временных характеристик, но и определенных параметров пространства. В координатах такого пространства формируются позиции и диспозиции вступающих в процесс взаимодействия субъектов, например «изоляция - контакт - сближение» или «соперничество - оппозиция - конфликт». В каждом из этих случаев для процесса взаимодействия необходимо пространство, в котором каждому из вступающих во взаимодействие партнеру предоставляется возможность соотнесения связанности задач и функция, степени автономности и взаимосвязи. Иными словами, в координатах пространства разворачивается сеть иерархических структур различных уровней зависимостей и связей.

Подобное определяется и в социально-психологическом пространстве организации. Здесь можно выделить целую систему его характеристик, которые опосредованы либо физическими свойствами, например, форма, расположение частей, либо системными свойствами организации, например, целостность, структурность, функциональная разнородность. Более того, следует иметь в виду наличие собственно психологических свойств в социально-психологическом пространстве организации. Вне взаимодействия и взаимоотношений людей, вне социальной деятельности организации социальнопсихологическое пространство не существует, так как оно всегда представлено объектными формами взаимодействующих партнеров в системе оценок, представлений и понимания. Иначе, социально-психологическое пространство понимается, переживается и оценивается каждым субъектом, который в него включен. Отсюда, мы 
можем представить разнообразие связей и отношений в социально-психологическом пространстве организации в единой схеме с критериями, отражающими свойства любой системы. Известно, что эти связи разделяются на одноуровневые и разноуровневые, однозначные и многозначные [11, с. 82].

Согласно данному утверждению, разнообразие однозначных связей можно разделить на три группы:

1. взаимно-однозначных связей, когда существует некоторая переменная или элемент А, связанный с переменной или элементом В, а этот элемент или переменная $\mathrm{B}$ - только с переменной или элементом A;

2. одно-многозначные связи существуют, когда одна переменная или элемент множества А связаны с несколькими переменными или элементами множества В;

3. много-однозначные связи имеют место, когда одна переменна или элемент множества В связана с несколькими переменными или элементами множества A.

В подтверждение изложенного находим у Т. Котарбинского, который обратил внимание на то, что каждый составной элемент имеет свою позицию в пространственном упорядочении, каждый частичный процесс из числа составляющих совокупность имеет свое место во времени, а различные элементы находятся в зависимости от других элементов. Всякая система при этом стремится к сохранению внутреннего равновесия, что не менее важно, к достижению необходимой цели [9, с. 79].

Отсюда можно сделать вывод, что критерием оценки социально-психологического пространства может быть некоторая форма упорядоченности ее элементов и структур, а основными параметрами их измерения целостность, структурность и автономия.

\section{Результаты и обсужление}

Исходя из проведенного нами теоретического анализа и, основываясь на обобщенных теоретических представлениях о характеристиках социально-психологического пространства как условии реализации межкультурного взаимодействия в организации, мы можем определить вектор эмпирических исследований. Во-первых, межкультурное взаимодействие может быть рассмотрено как организация совместной деятельности, то есть, как социальны процесс, в котором происходит обмен деятельностью или субъект-субъектное взаимодействие. Во - вторых, оно может быть описано параметрами системы межличностных связей и взаимоотношений. Если в первом случае речь идет не только о планировании совместной деятельности, но и о раз- делении функций между взаимодействующими субъектами, о координации и контроле этих функций, то есть функционально-ролевом взаимодействии, то во втором - об отношения, возникающих, как эмоциональные, непосредственные отношения, которые вытекают из задач и требований совместной деятельности.

Таким образом, принимая за основу эмпирического исследования субъект - субъектный подход, определяем задачей его первого этапа выявление специфики функционально-ролевого взаимодействия, или, как указывалось ранее - функциональной разнородности, а второго этапа - изучение отношений, или разнообразия связей и отношений в единой схеме межкультурного взаимодействия.

Анализ функционально-ролевых позиций сотрудников производственной сферы промышленных организаций (таблица 1) и в организациях строительства (таблица 2) показал следующее.

Распределение средних значений варьируется от 5,49 до13,57 баллов $(M x=8,53)$ в группе 1 (промышленные организациях производственной сферы) и от 4,93 до 12,94 баллов $(\mathrm{Mx}=8,21)$ в группе 2 (строительные организации производственной сферы).

Анализируя показатели по шкалами теста «Групповые роли» можно определить, что у сотрудников организаций производственной сферы (строительство (группа 2) полученные значения по шкалам «генератор идей», «оценщик идей», «организатор работы» и «исследователь ресурсов» приблизительно на один балл ниже, чем те же значения шкал у сотрудников промышленных организаций (группа 1). Значение по шкале «завершитель» приблизительно на два балла ниже, чем то же значение в коллективах строительных организаций (группа 2).

Кроме того, анализ распределения средних оценок групповых ролей в исследуемых организациях дает нам возможность сгруппировать их в содержательные блоки:

1. роли в выполнении поставленной задачи (оценщик идей (аналитик), исследователь ресурсов (эксперт), генератор идей);

2. роли в организации групповой работы (глава, организатор работы, завершитель);

3. роли для создания благоприятной социальнопсихологической атмосферы (формирователь, организатор группы).

Ролевой репертуар в исследуемых нами организациях определился таким образом. В организациях производственной сферы (промышленность) основными являются роли направленные на решение групповых 
Таблица 1.

Анализ функционально-ролевых позиций сотрудников промышленных организаций производственной сферы (по методике М. Белбина)

\begin{tabular}{|c|c|c|c|}
\hline \multirow{2}{*}{$\begin{array}{l}\text { № } \\
\text { П/ח }\end{array}$} & \multirow{2}{*}{$\begin{array}{c}\text { Функционально-ролевые позиции } \\
\text { во взаимодействии }\end{array}$} & \multicolumn{2}{|c|}{ Уровни репрезентации функционально-ролевых позиций. } \\
\hline & & $\begin{array}{c}\text { Высокий и средний уровень } \\
\text { распределения значений }\end{array}$ & $\begin{array}{c}\text { Низкий уровень распределения } \\
\text { значений }\end{array}$ \\
\hline 1. & Завершитель & 13,57 & - \\
\hline 2. & Организатор работы & 13,00 & - \\
\hline 3. & Организатор группы & 9,37 & - \\
\hline 4. & Формирователь & 7,21 & - \\
\hline 5. & Оцениватель идей & - & 6,94 \\
\hline 6. & Исследователь ресурсов & - & 6,36 \\
\hline 7. & Председатель & - & 6,36 \\
\hline 8. & Генератор идей & - & 5,49 \\
\hline
\end{tabular}

Анализ функционально-ролевых позиций сотрудников строительных организаций

Таблица 2. производственной сферы (по методике М. Белбина)

\begin{tabular}{|c|c|c|c|}
\hline \multirow{2}{*}{$\begin{array}{l}\text { № } \\
\text { п/ }\end{array}$} & \multirow{2}{*}{$\begin{array}{c}\text { Функционально-ролевые позиции } \\
\text { во взаимодействии }\end{array}$} & \multicolumn{2}{|c|}{ Уровни репрезентации функционально-ролевых позиций. } \\
\hline & & $\begin{array}{c}\text { Высокий и средний уровень } \\
\text { распределения значений }\end{array}$ & $\begin{array}{c}\text { Низкий уровень распределения } \\
\text { значений }\end{array}$ \\
\hline 1. & Завершитель & 12,94 & - \\
\hline 2. & Организатор работы & 9,84 & - \\
\hline 3. & Организатор группы & 9,70 & - \\
\hline 4. & Формирователь & 7,97 & - \\
\hline 5. & Оцениватель идей & - & 7,52 \\
\hline 6. & Исследователь ресурсов & - & 6,89 \\
\hline 7. & Председатель & - & 5,90 \\
\hline 8. & Генератор идей & - & 4,93 \\
\hline
\end{tabular}

задач («организатор работы» и «завершитель»). Отметим, что основные функциями при выполнении данных ролей - превращение идей в конкретные задачи и организация их выполнение в срок и до конца. Кроме того, функционально-ролевая позиция «организатор группы» относится к блоку ролей для создания благоприятной социально-психологической атмосферы и включает функции, содействующие согласию группы и улаживанию возникающих расхождений.

Дифференцированный анализ функциональноролевых позиций в исследуемых нами организациях производственной сферы свидетельствуют о том, что сотрудники промышленных организаций больше ориентированы на выполнение ролей, связанных с организацией групповой работы («завершитель», «организатор работы») и с созданием благоприятной социально-психологической атмосферы («организатор группы», «формирователь»).
Ориентация на реализацию функционально-ролевых позиций, связанных с выполнением поставленных задач («оценщик идей», «исследователь ресурсов»), в которых актуализируются аналитические и экспертные функции, имеет низкий уровень распределения значений (таблица 1). И еще в меньшей мере сотрудники промышленных организаций производственной сферы ориентированы на актуализацию своего творческого потенциала, на отказ от стереотипов и обычных методов работы, поиска инновационных решений. Такие тенденции, на наш взгляд, могут свидетельствовать о снижении реформаторской активности сотрудников, а, значит, и снижении тенденции к усовершенствованию организационной деятельности.

Детальный анализ представленных в таблице 2 данных ориентации сотрудников строительных организаций производственной сферы на основные функционально-ролевой позиции в организации показал, что они больше ориентированы на выполнения ролей, 
связанных с организацией групповой работы («организатор работы», «завершитель», «организатор группы») и на роли для выполнения поставленных задач («оценщик идей»).

В меньшей мере сотрудники в строительных организациях производственной сферы ориентированы на реализацию таких функционально-ролевых позиций, как «формирователь» и «председатель», которые предполагают функции лидера, принимающего решение и соединяющего усилие членов группы в единое целое. Еще в меньшей мере наблюдается ориентация на реализацию такой позиции, как «исследователь ресурсов», выполняющего функции эксперта. И на последнем месте по степени реализации находится такая функциональноролевая позиция, как «генератор идей», что, во-первых, предполагает наличие в организации сотрудников творчески мыслящих, а, во-вторых, содержание трудовой деятельности наполняет всей палитрой многообразия функций и возможностью актуализировать способности и талант. Как видно из приведенных данных, сотрудники строительных организаций производственной сферы менее всего ориентированы на самовыражение, на потребность работать не просто профессионально, а с высоким уровнем мастерства, переводя профессиональный опыт не столько в плоскость самовыражения, сколько в плоскость самоутверждения.

Далее, на следующем этапе исследования выявлялась система полифункциональных связей и взаимоотношения людей, основанных на отражающих процессах - процессах категоризации, непременным условием которых является ощущение общности, то есть ощущения того, что есть кто-то, как «Я».

Здесь отметим, что организация складывается как совместный организованный субъект, а, следовательно, и как некоторая социальная общность с мерами единства, разобщенности, и многого другого, что присуще человеческой общности. Но социальная общность не сводится к некоторой простой сумме личностей, в нее входящих. Отношения между людьми синтезируются в сложную гармонию организационных свойств. Включенная в сеть организационных отношений личность подчиняется законам этих отношений, сознательно следуя требованиям норм и правил, регулирующих ее поведение в организации. В самом общем виде это процессы организационной упорядоченности, они отражают основные механизмы перехода от энтропии к состояниям организационной целенаправленности, целеустремленности и целеполагания [7, с. 35 - 49].

Возвращаясь к изучению взаимоотношений и полифункциональных связей в межкультурном взаимодействии, заметим, что они строятся на строятся на осно- ве воспринимаемых или прогнозируемых отношений участников взаимодействия друг к другу, поэтому мы включили в анализ взаимоотношений сотрудников организаций три равноправных компонента: когнитивный, аффективный и конативный, как традиционно принято в психологической науке при рассмотрении проблем деятельности и общения [73; 128; 176].

Известно, что когнитивный компонент взаимоотношений и общения, который состоит из отдельных впечатлений и выводов, охватывает не только познание другого человека, но и самопознание [10 - 11; 14; 16; 23]. На этой основе происходят не только акты понимания внутреннего мира другого, но и акты самопонимания. Анализ этого компонента взаимоотношений в нашем исследовании дает возможность получить общие образы и стратегию построения межкультурного взаимодействия в организациях в целом. Аффективный компонент позволит понять модальность и силу взаимодействия сотрудников организаций, конативный - откроет реальный узор их поведения в общей системе межкультурного взаимодействия в коллективе.

Для изучения субъективных значений сотрудников организаций и субъективных значений их партнеров по взаимодействию мы использовали тест интерперсональной диагностики Т. Лири [15, с.125 - 129].

Анализ представлений в группе 1 (промышленные организации производственной сферы) и в группе 2 (строительные организации производственной сферы) о самих себе и о партнере, а также основных социальных ориентациях, которые определяют стиль поведения в межкультурном взаимодействии в организации, показал следующие результаты. Полученное различие в оценках работниками качеств реальных и идеальных партнеров во взаимоотношениях статистически достоверная по критерию U- Манна- Уитни (Mann-Whitney U) $[13$, c.173 - 176] на высоком уровне значимости (* $p<0,05$; $\left.{ }^{* *} \mathrm{p}<0,01 ;{ }^{* *} \mathrm{p}<0,001\right)$.

Средние значения субъективных оценок («Реальное Я») взаимоотношений варьируются в группе 1 (промышленные организации) - от 4, 69 до 6,79 баллов, в группе 2 (строительные организации) от 4,32 до 7,44 баллов. Средние значения оценок идеального партнера во взаимоотношениях в группе 1, по аналогии с предыдущим, варьируются от 3,20 до 7,30 баллов и в группе 2 от 2,23 до 7,09 баллов. Таким образом, сотрудники строительных организаций (группа 2) оценивают качества идеального партнера в отношениях в среднем приблизительно на один балл выше, чем те же качества «Я - реального», а в оценках этих же качеств у работников промышленных предприятий мы наблюдаем различие в два балла. 
Кроме того, степень выраженности свойств по шкалам «Реальное - Я» и «Идеальное - Я - партнер по взаимодействию» характеризует адаптивный вариант поведения сотрудников в исследуемых организациях, поскольку диапазон распределения свойств в строительных организациях находится в пределах от 4,32 до 7,44 в «Реальное - Я» и от 2,23 до 7,26 в «Я - идеальное партнер по взаимодействию», что, в свою очередь, соотносится с первой степенью диапазона проявления свойств. В промышленных организациях диапазон распределения свойств находится в пределах от 4,69 до 6,79 по «Я - реальному» и от 3,20 до 7,3 по шкале «Я - идеальное - партнер по взаимодействию», что также свидетельствует об адаптивности поведения в межкультурном взаимодействии.

Анализ результатов средних значений количественных показателей по характеристике «Реальное - Я» в промышленных организациях (группа 1) показал, что преобладает «сотрудничающий - конвенциальный» тип поведения в межкультурном взаимодействии [15, с.131]. Он характеризуется тем, что большинство работников данных предприятий определяют себя причастными к проблемам, успехам и неудачам коллектива. Осознавая свое единство и целостность, которая проявляется в ощущении «мы» - ощущении социальной общности и единства мыслей, оценок, целей, интересов, они стремятся к согласованности действий, преодолению возникающих трудностей, к решению новых задач.

В строительных организациях производственной сферы по субъективным оценкам результатов исследования («Реальное-Я») тип отношений в целом можно классифицировать, как «ответственно- великодушный» (альтруистичный [там же, с.130]. Основными параметрами, определяющими его, являются чуткость, самоотдача, бескорыстие, служение идеалу, эмпатия, эмоциональная реактивность. Кроме того, данный тип отношений характеризуется выраженной потребностью отвечать социальным нормам поведения, склонностью к идеализации и гармонии взаимоотношений, экзальтацией своих убеждений, выраженным эмоциональным вовлечением, легкостью внедрения в разные социальные роли, гибкостью в контактах, коммуникабельностью, доброжелательностью, жертвенностью, стремлением к деятельности, полезной для всех.

Для более полного описания отметим, что согласно показателям по данному параметру сотрудники строительных организаций в межкультурном взаимодействии ориентированы на альтруизм, проявление которого связан с мотивами моральных обязательств и сочувствия [там же, с.129]. На наш взгляд, в первом случае сотрудники этой категории ориентированы на альтруистические поступки ради этического удовлетворения, повышения самооценки. Их помощь носит скорее жертвенный характер. Во втором случая альтруизм сотрудников связан с отождествлением и сопереживанием, а помощь характеризуется повышенной ответственностью.

Далее, полученные результаты по характеристике «Идеальное - Я - партнер по взаимодействию» выявляют совпадение оценок с характеристикой «Реальное - Я» у сотрудников строительных организаций. Похожесть мыслей относительно линий поведения в данном случае свидетельствует о наличии конгруэнтности, которая предполагает взаимность ролевых ожиданий, созвучность их переживаний, возникновение доверия и симпатии.

Работники промышленных организаций (группа 1), по аналогии с предыдущим, наоборот, ориентированные на общение с «властно-лидирующим» (авторитарным) типом партнера [15, с.133]. Для наиболее точного описания отметим, что данный тип поведения в межкультурном взаимодействии характеризуется оптимистичностью, скоростью реакций, высокой активностью, выраженной мотивацией достижения, тенденцией к доминированию, повышенным уровнем притязаний, легкостью и скоростью в принятии решений. Это реагирование по типу «здесь и сейчас», с активным влиянием на окружение, завоевательной позицией, стремлением вести за собой и подчинять своей воле других.

Кроме того, мы рассматривали тип поведения в межкультурном взаимодействии сотрудников производственной сферы в целом с позиции трехдиапазонного проявления каждого свойства: от адаптивного до дезадаптивного варианта поведения. Как было показано выше, сотрудники строительных организаций производственной сферы ориентированы на «ответственно-великодушный» (альтруистический) тип поведения в характеристике «Реальное - Я». Адаптивный вариант поведения оказывается в диапазоне чуткость - бескорыстие - жертвенность. Кроме чуткости, согласно показателям соотношения шкал $(0,581)$, работникам данной сферы присущие сочувствие, способность к сопереживанию и доступность при контакте. Такими же они видят и партнеров по взаимодействию: соотношение значений шкал $(0,301)$ по характеристики «Идеальное - Я партнер по взаимодействию».

Продолжая анализ моделей взаимодействия по соотношению шкал «Реальное - Я» у сотрудников промышленных организаций производственной сферы, мы определили, что адаптивный вариант поведения у данной категории сотрудников оказывается в диапазоне добросердечность - несамостоятельность - чрезмерный конформизм [15, с.129]. А отношение значений шкал $(0,801)$ характеризует демократичность и гибкость по- 
ведения с учетом конкретной ситуации взаимодействия. Полученные показатели оценки партнера по взаимодействию у этой же категории сотрудников свидетельствуют об адаптивном проявлении свойств в диапазоне доминирования - властолюбие - деспотизм. Отношение значений шкал $(1,201)$ означает преобладание лидерских качеств, стремление занять руководящую позицию, инициативность и ответственность.

\section{Выводы}

Итак, на основе результатов этой части нашей ра- боты, мы можем утверждать, что в организациях производственной сфера определяется «сотрудничающий - конвенциальный» (дружелюбный) и «ответственно - великодушный» (альтруистичный) типы поведения во взаимоотношениях в коллективах. Созвучность переживаний, стремление к согласованности действий, взаимность ролевых ожиданий, которые характеризуют данные типы отношений, свидетельствуют о наличии эффекта конгруэнции, как параметра социально-психологического пространства, в условиях которого будут разворачиваться полифункциональные связи в межкультурном взаимодействии сотрудников.

\section{ЛИТЕРАТУРА}

1. Бергер П. Социальное конструирование реальности. Трактат по социологии знания / П. Бергер, Т. Лукман; [пер. Е.Д. Руткевич]. - М.: Медиум 1995. $323 c$.

2. Бурдье П. Социальное пространство и символическая власть / П. Бурдье. - M.: Socio-Logos, 1994. — C. 181 - 207.

3. Гидденс Э. Последствия современности / Э. Гидденс. [пер. с англ. Г.К. Ольховникова, Д.А. Кибальчича; вступ. статья Т.А. Дмитриева]. - М.: Издательская и консалтинговая группа «Праксис», 2011, - 352с.

4. Гидденс Э. Устроение общества: Очерк теории структурации. - 2-е изд. / Э. Гидденс - М.: Академический проект, 2005. - 350с.

5. Гофман А.Б. Существует ли общество? От психологического редукционизма к эпифеноменализму в интерпретации социальной реальности / А. Гофман // Социол. исслед. 2005. № 1. - С.16- 26.

6. Журавлев А.Л. Психология коллективного субъекта / А.Л. Журавлев // Психология индивидуального и группового субъекта [под ред. А.В. Брушлинского, М.И. Воловиковой]. - М.: Изд-во Ин-та психологии РАН, 2002. - С.51- 81.

7. Казмиренко В.П. Социальная психология организаций: Монография. / В.П. Казмиренко. - К.: МЗууП, 1993. - 384с.

8. Козер Л. Мастера социологической мысли. / Л. Козер. - М.: Норма, 2006. - 205с.

9. Котарбинский Т. Трактат о хорошей работе / пер. с польск. / Т. Котарбинский. - М.: Экономика, 1975. - 270 с.

10. Леонтьев А.А. Психология общения / А.А. Леонтьев. - [3-е изд.] - М.: Смысл, 2000. -365 с.

11. Мерлин В.С. Очерки интегрального исследования индивидуальности / В.С. Мерлин. - М.: Педагогика, 1986. - 253 с.

12. Мерлин В.С. Взаимоотношения иерархических уровней в системе взаимосвязей «Человек - общество» / В.С. Мерлин // Вопросы психологии -1975. № $5 .-$. $.3-12$.

13. Наследов А.Д. Математические методы психологического исследования // А.Д. Наследов. - СПб.: Речь, 2004. - 392.

14. Позняков В.П. Психологические отношения субъектов совместной жизнедеятельности / В.П. Поздняков // Знание. Понимание. Умение.2013. №1. C. $167-174$.

15. Практическая психодиагностика. Методики и тесты / [ред. Д.Я. Райгордский]. Самара: Издательский Дом «БАХРАХ», 1998. - 672 с.

16. Пригожин А.И. Организация: системы и люди / А.И. Пригожин. - М., 1983. -176 с.

17. Сорокин П.А. Человек. Цивилизация. Общество./ П.А. Сорокин. - М., 1992. - С.298 - 301.

18. Симонова 0.А. История социологии XX века : избранные темы : учеб. пособие для студ. вузов / 0.А. Симонова. - М.: Логос, 2008. - 205 с. - (Новая университетская библиотека).

19. Роберти Е.В. Новая постановка основных вопросов социологии: избр. / Евгений де Роберти; редкол. сер. : А.О. Бороноев (отв. ред.), И.А. Голосенко, В.В. Козловский; сост. А.О. Бороноев и М.В. Ломоносова; СПб. гос. ун-т, Фак. социологии, Социолог. 0-во им. М. М. Ковалевского. - М.: Алетейя, 2008. 394 c.

20. Ритцер Дж. Современные социологические теории / Дж Ритцер СПб., 2002. - 321с.

21. Луман Н. Понятие общества / Н. Луман // Проблемы теоретической социологии. — СПб.: Петрополис, 1994. - С. 25 - 42.

22. Фетискин Н.П. Социально-психологическая диагностика развития личности малых групп / Н.П. Фетискин, В.В. Козлов, Г.М. Мануйлов. - М.: Изд-во института Психотерапии, 2002. - 490 c.

23. Хоуманс Дж. Социальное поведение как обмен / Дж. Хоуманс // Современна зарубежная социальная психология. - М., 1984. - 321с.

(с) Король Ольга Феликсовна (korololga2008@gmail.com). 